\title{
A CONSTITUIÇÃO DA SUBJETIVIDADE E A ILUSÃO DO FINALISMO: ELEMENTOS DE UMA TEORIA DA IDEOLOGIA
}

Alexandre Arbex Valadares

Resumo: Este artigo propõe estabelecer uma correlação entre a concepção de Spinoza acerca da imaginação e a teoria da ideologia de Althusser. Compreendida em seu modo de funcionamento e nos seus efeitos sobre a percepção dos homens acerca de seu corpo, de suas ideias e das coisas que a afetam, a imaginação, segundo a acepção spinozista, passa a constituiria a forma da consciência subjetiva ao operar no mundo da política. Marcada pela regularidade e previsibilidade dos processos causais e pela reprodução das relações, a ordem política se afiguraria à imaginação como uma ordem teleológica, cuja repetição fixaria, como verdades universais, as ideias das imagens das coisas na forma com que estas se apresentariam mais recorrentemente à percepção dos homens. À estabilidade das relações e das imagens sob as quais os homens as representam corresponderia a estabilidade dos modos de pensar sob os quais eles representam a si mesmos no interior da ordem política. Os conteúdos da consciência - da imaginação politicamente estruturada - seriam, desse ponto de vista, sempre conteúdos ideológicos.

Palavras-chave: Spinoza, imaginação, Althusser, ideologia.

Para Spinoza, o conhecimento que os homens têm do corpo e da mente resulta da operação espontânea pela qual a mente, que é ideia do corpo, constitui a si mesma como objeto de uma ideia. A mente é a ideia

* Doutorando em Filosofia pela Universidade Federal do Rio de Janeiro; membro do Grupo SpiN: estudos sobre Spinoza e Nietzsche. 
das afecções do corpo; mais exatamente, ela é um complexo de modos de pensar correspondente ao conjunto atual das modificações dos estados corporais. Da mesma forma, a consciência, ou a ideia da mente acerca de si mesma, é a ideia da ideia dessas afecções, ou melhor, é a ideia que a mente tem de si mesma na medida em que se percebe pelas ideias das afecções do corpo (Spinoza 6, E, II, 12-23). ${ }^{2}$

Ao perceber uma coisa, isto é, ao ser, em virtude de uma ideia de afecção, determinado a considerar uma coisa como existente, um homem percebe, ao mesmo tempo, sob o prisma dessa ideia, sua maneira presente de pensar e de existir. Um homem assiste a uma missa ou segue um discurso num seminário de filosofia: todas essas coisas lhe são presentes na medida em que o modificam materialmente. Ele é determinado a considerá-las como existentes em ato - ou a imaginá-las - em razão das afecções que elas produzem sobre seu corpo e das ideias dessas afecções por meio das quais a mente as percebe, ou antes, por meio das quais a ideia do corpo, que é a mente, se atualiza. Em resumo, uma afecção é uma imagem material ou uma modificação sensível cuja percepção envolve uma imagem do corpo. Uma ideia de afecção é uma ideia de uma imagem.

O corpo modifica-se conforme as afecções e as relações em que elas se dão: na missa, o homem se ajoelha, admira o altar; num seminário, ele corrige a postura quando sente que o amolecimento do corpo coincide com a distração da inteligência. Nessas variações, o homem percebe as modificações do corpo pela sucessão das coisas cujas imagens, ou afecções, a sua mente é determinada a considerar. Mas, além de perceber o corpo e de afirmá-lo como existente a partir de sua imagem, a mente percebe simultaneamente a ideia dessa imagem, ou a ideia do corpo, e afirma essa ideia como existente. Traduzindo, para o ponto de vista da imaginação subjetiva, uma tese de Matheron (12, p. 68), pode-se dizer que a mente percebe-se a si mesma, converte a ideia que ela é em objeto de uma ideia que ela tem, como sujeito, e que está, para ela, na mesma relação que uma afecção está para uma ideia de afecção; noutros termos, a mente se "imagina". A mente afirma, então, não o corpo tal como ela percebe pelas ideias das afecções, mas sua própria existência como ideia, e, assim, como que se apropria de si mesma. Se as ideias de afecções são espontaneamente imaginadas na mente, esta supõe que, ao converter essas imaginações em objeto de outras ideias, isto é, ao objetivá-las como ideias de ideias, autonomiza-se em relação às coisas representadas e entra, como sujeito, na posse formal do pensamento.

Spinoza denuncia que essa consciência subjetiva da imaginação não encerra conhecimento adequado algum: na medida em que se limita ao conteúdo de uma afecção e se inscreve em uma relação determinada entre seu corpo e a coisa que o afeta, essa ideia não dá ao homem senão um conhecimento parcial da coisa, de seu corpo e sua mente (Spinoza 6, E, II, 29-31). Para Spinoza, conhecer uma coisa é conhecê-la em sua causa. A causa pela qual se explicam os efeitos que uma coisa produz em nós é a natureza atual dessa coisa. As ideias de afecções, visto que são ideias dos efeitos das coisas sobre nós, encadeiam na mente apenas a imagem dessas modificações, ou a imagem de nosso corpo a partir das afecções a que ele é relacionado, sem todavia exprimir a natureza das coisas que o afetam. Pode-se assim dizer que a ideia de uma afecção é conhecimento parcial porque é a ideia de um efeito alienado de sua causa.

A mente que imagina, porém, não está advertida dessa insuficiência (Pires Aurélio 13, p.66): como ela recolhe imagens parciais das coisas, a mente é privada das ideias que, exprimindo a causa de tais imagens, a fariam notar a parcialidade desse conhecimento. O que fará, então, a imaginação? Suspenderá provisoriamente todos os juízos? Não: ela suprirá essa insuficiência através de uma inversão. A imaginação reterá os efeitos das coisas, as ideias das afecções, e os tomará como causa final da ação 
delas (Deleuze 4, p. 29). Como a imaginação abstrai, por não poder percebêlas, as causas externas das ideias de afecções que ela percebe e que dão a forma presente da consciência, ela então, em vez de relacionar os efeitos dessas afecções à natureza das coisas que a afetam, julgará que tais efeitos predeterminam ou explicam as suas afecções correspondentes; noutros termos, é como se a verdade das coisas estivesse na consciência que temos delas, e elas não fizessem mais que encontrar, na nossa imaginação, como seu destino, a representação sob a qual essa verdade se faz reconhecer.

A ilusão da subjetividade conjuga-se, aqui, à ilusão do finalismo: para a imaginação, que percebe o mundo por ideias de afecções, é como se os efeitos das coisas externas, tendo percorrido longas genealogias sob as leis universais de causalidade, deixassem os domínios da natureza ao penetrar a jurisdição da consciência, para realizar aí o ciclo de sua finalidade. Esse movimento opera o corte idealista que aparta a existência do indivíduo humano da vida das coisas naturais, e instala, no império da natureza, o império do Homem (Spinoza 6, E, III, Pref.; TP, 6).

Aconsciência subjetiva inspira, pois, uma ordem finalista de explicação do mundo (Deleuze 4, p. 64). Partindo das ideias que nos são imediatas as ideias das afecções -, imaginamos, ignorando as causas verdadeiras que as vinculam às naturezas dos corpos externos, que essas ideias se explicam pela consciência que temos delas, e derivamos daí uma relação causal entre as ideias que se apresentam à mente e a consciência pela qual as fazemos "nossas". A mente imagina então constituir, por sua autonomia, os objetos de seu pensamento. Essa inversão, operada na imaginação, tem, porém, importância essencial, por assim dizer prática, à percepção dos homens acerca de suas relações; é ela que lhes permite criar uma ordem de inteligibilidade do mundo, ainda que esta não corresponda à ordem de produção do real.

Para criar uma ordem de inteligibilidade do mundo - e toda ordem é suspensão do aleatório -, a imaginação sobrepõe, às relações aparentemente fortuitas, uma associação coordenada entre as ideias das coisas. Como uma ordem reclama uma norma, cumpre haver um critério que presida às associações de ideias e as organize de tal sorte na mente que elas componham um sistema de explicação do mundo que reproduza, tão fielmente quanto possível, a ordem comum de percepção das coisas (Spinoza 6, E, II, 29, corolário.), a ordem da práxis. Para o homem que imagina o mundo, esse princípio ordenador capaz de conferir sentido às coisas e suas relações deve situar-se no fato comum de todas elas se fazerem representar, como ideias de afecções, na sua mente, e assim lhe restituírem a todo instante uma imagem de seu corpo, da mente que o percebe como seu e que, ao percebê-lo, percebe a si mesma. A consciência subjetiva se apresenta, então, ao homem como eixo fixo em meio ao fluxo contingente dos eventos, e permite à imaginação desfraldar seu mapa de pólos invertidos: substituindo o que ignora - as ideias das causas das afecções -, pelo que percebe as ideias de seus efeitos -, a imaginação estende sobre o mundo uma ordem finalista centrada na autonomia da consciência.

Assim, ao considerar as coisas da perspectiva das ideias de seus efeitos, a percepção do homem acerca do mundo é matizada pela percepção que tem de si mesmo. Representamos as coisas apenas na medida em que nos afetam, e elas nos afetam apenas na medida em que reconhecemos, nas suas imagens, uma imagem de nós próprios; dito de outro modo, as ideias de afecções representam as coisas na sua relação conosco e a nós na nossa relação com elas. Tais relações são imaginárias porque mediadas pela consciência subjetiva, que é a imagem em que nos representamos como sujeitos no centro da ordem de explicação do mundo segundo a qual as coisas podem ser conhecidas à luz de nossa natureza. Podemos, com base nisso, dizer que se acham, na teoria spinozista da imaginação, os elementos que, para Althusser (3, p. 72), definem as 
ideologias: representação imaginária do real, inversão das relações reais e ilusão do sujeito consciente como seu centro ordenador.

A analogia não é perfeita, e o próprio Althusser, que a sugere, não se ocupa dela demasiado. Há, a princípio, uma diferença de monta: em Spinoza, a imaginação se apresenta inicialmente como traço característico do homem individual, ao passo que a ideologia, para Althusser, não pode ser entendida fora das relações políticas tomadas em conjunto. Essa diferença, porém, pode ser resolvida fazendo encarnar esse indivíduo imaginativo - pensado em "estado de natureza" na segunda parte da Ética - na teoria política de Spinoza.

Com efeito, como diz o TP (II, 15), os indivíduos humanos não existem nem podem ser concebidos isoladamente: o conatus, essência atual em virtude da qual eles perseveram no ser, não pode efetivar-se se, para isso, conta somente com a potência singular ou o direito natural individual. A potência singular, considerada em si mesma, é uma abstração, ineficaz frente à potência das coisas a cujas afecções o corpo humano está suscetível. Para que ela se efetive e possa afirmar como coisa existente como corpo - a essência singular que nela se exprime, a potência singular de um homem precisa compor-se a outras potências singulares sob dadas relações: relações de produção das coisas necessárias à conservação dos seus corpos, relações de resistência às afecções nocivas a que todos os corpos semelhantes estão sujeitos. Uma relação é dita de composição se dela resultam efeitos favoráveis à afirmação da existência de um homem, à expressão de seu conatus individual. Mas com que indivíduos um homem tem mais ocasião de estabelecer relações de composição? Com aqueles cujas naturezas têm mais propriedades em comum com a sua, de sorte que, agindo para conservar a si mesmos, operam efeitos úteis também a ele. Ora, o que há de mais parecido na natureza com um homem é outro homem: o alimento que um homem produz para si também deve servir a outro, o agasalho que este cose para proteger-se do frio deve aquecer também ao outro. Por isso, porque seus corpos têm muitas propriedades semelhantes, para um homem nada é mais útil que outro homem (Spinoza 6, E, IV, 18, escólio).

O que há de comum aos homens, então, é a necessidade contínua de produzir sua existência e a impossibilidade de fazê-lo sozinhos, e é nessa medida que Spinoza afirma nada objetar aos filósofos que consideram o homem um animal político. As relações de composição que os indivíduos são determinados a estabelecer entre si para realizar seu conatus podem então ser entendidas como relações coletivas de produção das existências humanas singulares. O processo de constituição de relações de potência entre homens para a produção comum de suas existências singulares funda sua maneira de existir na Natureza como uma existência necessariamente política.

As relações de composição de potências constituem, então, um modo coletivo de existência, um "indivíduo" mais complexo - o político. O político seria, então, um indivíduo composto de relações de potências através das quais suas partes - homens singulares - operam em comum os efeitos necessários à sua permanência em vida. Essas relações de produção são as relações constitutivas do político, cuja existência, como indivíduo complexo, se produz através da reprodução dessas relações. Nas suas relações de produção ou, o que é o mesmo, nas suas relações políticas, os homens não produzem uma existência em si, mas o modo determinado pelo qual existem e agem no político. Assim, ao operarem uns com os outros segundo as relações políticas sob as quais sua existência se produz, os homens reproduzem o modo de ser desse indivíduo político através da reprodução das relações que o caracterizam - as relações de produção. A produção da existência individual envolve a reprodução da existência do político na medida em que as relações através das quais elas se realizam são as mesmas. 
Existir, diz Althusser, é reproduzir-se (Althusser 1, p.240), e se o modo de existir de um indivíduo é seu modo de produção, o modo de produção dos homens é o modo de produção do político. O homem é efeito do conjunto em cujas relações sua existência é concebível; ao mesmo tempo, através dessas relações, os homens produzem as condições de determinação de sua produção, isto é, as condições que os levam a produzir sua existência de certo modo. Essa dinâmica de produção-reprodução do ser político estabiliza as relações dos homens em uma ordem de regularidade.

Mas, em termos spinozistas, o que são as condições que dispõem os homens a operar nessas relações? São afecções. Os efeitos que as afecções os determinam a operar se explicam ou pela natureza dessas afecções ou pela natureza dos homens modificada por afecções. Modificados por uma afecção, os homens operam efeitos que exprimem sua potência de existir em relação ao que os afeta; existem, não em termos absolutos, mas de modo determinado pela relação em que sua existência se produz (politicamente). Ao mesmo tempo, a ideia dessa afecção, a imagem do corpo que os afeta determina-os a considerar esse corpo presente na forma dessa relação. Ora, se as ideias representam na mente as relações que temos com as coisas que nos afetam, está claro que tais representações são tanto mais estáveis quanto mais constantes são as afecções ligadas a tais relações. Afetados seguidamente por afecções semelhantes, sujeitos ao contato regular das mesmas imagens, reiteramos na mente os mesmos agregados de ideias: a recorrência das afecções, na ordem da produção-reprodução das relações políticas, corresponde à recorrência das ideias de afecções; a regularidade da prática material encontra equilavente na composição estável dos modos de pensar essa prática como existência.

A sujeição regular de um homem à sucessão previsível de afecções ou imagens materiais que descrevem o ciclo de reprodução das relações políticas sedimenta na sua imaginação uma estrutura estável de representação das coisas que ele é determinado a perceber, e na ordem em que elas se oferecem à sua percepção. Vimos que é a partir da imagem de nosso ser individual que se forma a ideia reflexiva espontânea que funda a consciência subjetiva como centro de uma ordem finalista. Na política o conteúdo ideal dessa consciência - sua imagem subjetiva, as representações das coisas - é reiterado como sistema aparentemente imutável de ideias, correspondente à dinâmica conservadora das relações: como um pano de fundo entretecido de ideias sempre associadas nos mesmos motivos e imagens, a consciência do homem na política é a representação constantemente restaurada das relações através das quais sua existência se produz. A consciência é a imaginação politicamente estruturada.

Para Spinoza como para Althusser, a consciência é uma percepção de mundo inadequada, invertida, arraigada à ilusão da autonomia do sujeito e determinada de fora pelas relações que ela espontaneamente representa. Os três graus de alucinação do real abrangidos na teoria da ideologia de Althusser - (1) representação > (2) imaginária > (3) das relações imaginárias dos indivíduos com o real - correspondem, em certa medida, a três passos do que se poderia chamar teoria spinozista da formação da consciência na imaginação. Esta se compõe de: (1) ideias/consciência (2) das ideias/percepção > (3) das imagens das coisas (Althusser 1, p. 203). Se parece complicado conciliar a ideia spinozista de que as representações mentais dos homens variam ao acaso das afecções, por outro lado conjecturar que a imaginação tende a se estabilizar na forma de uma consciência subjetiva em virtude da reprodução regular das relações no político concorda com o fato de que as ideias das afecções afirmam continuamente, para um homem, uma imagem de sua natureza, e que esta somente pode ser concebida como existente no político.

Da perspectiva espinosista, a consciência é externamente determinada em seu conteúdo, isto é, nas ideias de afecções ou imagens 
materiais que, por contínua reiteração, estruturam o repositório de representações estáveis de entre as quais sobressai, como ponto comum de referência, a imagem de auto-identificação do sujeito. Em Althusser, as consciências subjetivas são constituídas através da interpelação exterior de uma ideologia dotada de existência material. Essa materialidade não é da mesma espécie que a de uma pedra - de um "fuzil", diz Althusser -, assim como o substantivo "pobreza" não é tão abstrato quanto a hipotenusa; essa materialidade concerne ao fato de que a ideologia não pode ser dissociada do aparelho de Estado na qual se efetivam as relações que ela representa e das quais os homens participam, porque é através delas que produzem sua existência.

Tal como Spinoza afirma que é impossível que, modificados por uma afecção, não se siga em nós a ideia dessa afecção, Althusser nota que a prática material dos homens se associa, neles, inelutavelmente, a uma representação mental correspondente. Os homens não representam mentalmente senão o que percebem, e só percebem o que, ao afetálos, estabelece com eles uma relação. Para Spinoza, nossa essência é, também, material: imaginamos porque somos compostos de um corpo. As associações de ideias que compõem a consciência, estrutura estável de representação das relações políticas, têm uma existência material porque, dado que a essência dos homens envolve modos de extensão e pensamento, não se pode conceber modificação corporal a que não corresponda uma modificação mental. Da mesma forma, ao afirmar que Deus é coisa pensante e material, Spinoza (6, E, II, 1-2) não está a dizer que o pensamento se amolda à matéria que representa nem que esta só existe enquanto objeto de pensamento: o que ele assinala é que, tal como os corpos, na medida em que são pensáveis, têm existência ideal, também as ideias, visto que são concebíveis e podem ser afirmadas como realmente existentes, têm existência material.
A proposição spinozista segundo a qual Deus é coisa material encontra ressonância na tese althusseriana acerca da materialidade das ideias. Althusser sustenta que as ideias são materiais (Althusser 1, p. 280), que a ideologia, como sistema de ideias imaginativas através das quais os homens percebem suas relações com as condições de existência, tem uma materialidade própria. A ideologia sempre se inscreve na prática material que a realiza, da mesma maneira que essa prática se representa sob forma de ideologia. Por essa razão, afinal, toda relação econômica, material, é dita, simultaneamente, relação político-ideológica: apreender uma relação social ora da perspectiva material ora da perspectiva ideológica, considerando-a respectivamente como momento da estrutura ou da superestrutura, não implica dar chancela a uma concepção paralelista de mundo, mas, antes, chama a atenção para o fato de que, assim como a essência singular, na filosofia spinozista, pode ser explicada por mais de um atributo, a essência do político pode ser concebida por um ou mais "atributos". De outra parte, a materialidade das ideias é o que resta oculto sob a ilusão da autonomia de consciência: incutindo nos sujeitos a crença de que suas representações mentais são lavra legítima de sua inteligência criadora, tal ilusão abstrai as causas materiais das ideias de imaginação. A consciência - assimilação subjetiva da ideologia, para Althusser - é também efeito da inversão das relações de determinação das ideias: os homens estimam que, conscientes das relações que os afetam e condicionam suas práticas materiais, passam a ter parte nelas, não por necessidade, mas adesão, e tanto mais se persuadem dessa autonomia quanto mais ignoram as causas que os determinam a considerar as coisas de certo modo e a agir, com respeito a elas, segundo esse modo determinado de considerá-las.

Nas ideias de afecções, o verdadeiro confunde-se, na forma da simples presença da coisa, com o fenômeno espontâneo de sua aparição. Nossa sujeição às afecções, conjugada à abstração de suas causas, induz-nos 
a julgar que, considerando a imagem material de uma coisa “dada", podemos formar a seu respeito um conhecimento "concreto". Mas por mais concreta que seja a coisa que buscamos conhecer, considerá-la-emos sempre de uma perspectiva abstrata se não a referirmos a suas causas, seu modo de produção. Assim, por exemplo, no indivíduo político "capitalismo", as mercadorias afetam-nos normalmente na condição de valores-de-troca designados sob a forma "preço". A ideia da afecção dissimula sua causa: com base nessa ideia refletida da imagem material "preço", não conhecemos que a afecção que nos determina considerar a mercadoria como valor-de-troca resulta da relação entre trabalho social abstrato, cristalizado na forma "valor" do equivalente-geral (dinheiro) e o trabalho concreto cristalizado na forma "valor-de-uso" de outra mercadoria. Percebemos o valor-de-troca, o preço, como um efeito alienado de sua causa, de sua produção, e investido num objeto como se fora sua essência: é a sujeição às afecções reiteradas nas relações características do indivíduo político "capitalismo" que acaba por fazer necessária a ilusão pela qual a relação entre os trabalhos sociais se apresenta na forma de uma relação entre coisas, como assinala Marx ao tratar do fetichismo da mercadoria em $O$ Capital (I, 1, seção 4).

A ideologia e a imaginação, presas à ilusão das imagens materiais, supõem que o conhecimento é autônomo em relação a toda a exterioridade: a imaginação povoa a consciência de universais, abstraídos da singularidade das coisas representadas, e crê consistir nisso a razão; a ideologia, constituindo a consciência subjetiva através da reprodução material de suas representações imaginárias, empresta a estas o valor de verdades eternas porque aliena as condições históricas de sua produção. A consciência subjetiva constitui-se na medida em que se faz presente na imaginação individual o reconhecimento espontâneo de um mundo regular, onde as coisas freqüentam as mesmas relações e são determinadas a promover as mesmas conseqüências. Por efeito da imaginação, essa previsibilidade da dinâmica social oculta o seu caráter de produção sob a aparência de instituição: assim como, na descoberta de uma lei natural, a observação contínua de seus efeitos e o estabelecimento de padrões de regularidade levam a concluir que dado evento sempre seguiu e há de seguir idêntico curso por toda a eternidade, também no político a percepção constante dos mesmos efeitos e imagens materiais persuade as consciências de que a forma dominante pela qual se realizam as relações entre os homens é a forma universal. No fundo comum da consciência subjetiva, a imaginação abstrai as causas das coisas cujos efeitos percebe, e a ideologia imprime uma constelação de verdades eternas que denegam o caráter histórico de sua produção.

A realização da ideologia depende da sua materialização. No político, os indivíduos tendem a operar os mesmos efeitos reais nas suas relações e a conservar, através deles, o modo de ser do indivíduo político que constituem. Esses efeitos tocam ao corpo e à mente, tanto na forma de uma reiteração espontânea das práticas materiais quanto na conservação da composição da consciência em que tais práticas são representadas. A reprodução dos efeitos pelos quais os homens conservam seu modo de ser envolve afecções, estruturas materiais com que eles necessariamente se relacionam porque não podem conceber, sem elas, as práticas materiais que conservam sua existência. Por isso, eles tendem a associar seu modo de existir a um modo de produzir a existência que não se pode dar fora das relações e estruturas que caracterizam o indivíduo político. Sob a forma da consciência, a imaginação é, por natureza, conservadora: ela nos faz conservar a vida que levamos e a percebê-la como a única vida que podemos levar.

A materialização de uma ideologia produz no político a assimilação das imaginações individuais na forma da mesma consciência subjetiva ou visão de mundo. Pode-se dizer que a tese althusseriana da materialidade 
da ideologia se anuncia no esboço de uma teoria da materialidade da imaginação desenvolvida por Spinoza no capítulo V do TTP, onde se demonstra que, materializado na sua simbologia, o imaginário das cerimônias religiosas (e civis) ajuda a consolidar suas instituições. Mas na regularidade do político, a estabilização da imaginação na forma de consciência subjetiva envolve mais que a inversão dos efeitos em causas: no tecido homogêneo da existência política, as representações que os indivíduos fazem espontaneamente de suas ações passam a se lhes afigurar como projeções dessas ações. Como opera por mecanismo de imaginação, a consciência subjetiva não pode senão deduzir que a existência das coisas atende a uma finalidade, que elas são determinadas em função de seus efeitos. A previsibilidade comuta-se em necessidade. Sem ter em conta que a consciência só reflete a ordem comum segundo a qual percebemos as relações, imaginamos que estas se apresentam, por coincidência, sob uma ordem tal que podemos explicá-las pela consciência que temos delas. Se a imaginação não pode ser dita gênero adequado de conhecimento, ela pode ser chamada "gênero de reconhecimento", como propõe Althusser (1, p. 211) acerca da ideologia: a imaginação opera com ideias-prontas, percepções “evidentes”, que replicam, para confirmá-las, as representações fixadas por ideias das afecções ou interpelações materiais em uma consciência politicamente estruturada. A ideologia dominante é a substância do consenso.

Mas a ideologia e a imaginação não são rigorosamente negativas: elas são, antes, os únicos pontos de partida para a transformação política. Marx, no prefácio de Para a crítica da economia política, assinala ser na esfera da ideologia que os homens se fazem conscientes do conflito entre forças produtivas e relações de produção, sem pressupor, é claro, que essa consciência lhes dá todo conhecimento do processo histórico. E Spinoza não cessa de advertir que a imaginação é necessária em virtude de suas causas e, por isso, encerra um grau de positividade: é pelo conhecimento das causas da sua imaginação que um homem - sem deixar de imaginar pode ter um conhecimento das causas das afecções que sofre. A razão, para Spinoza, é um modo de conhecer que, como tal, sofre a ação contínua de outros modos de pensar, como a imaginação e as paixões.

Conta certa anedota que São Tomás de Aquino, recolhido a um aposento para redigir a Suma teológica, ergueu-se de súbito para ver o céu quando um frade gaiato lhe veio dizer: "Senhor, mirai, um boi a voar!"; o exemplo ilustra a necessidade que nos determina a imaginar presente o que a ideia dessa afecção propõe. De resto, o caráter necessário da imaginação põe a descoberto a necessidade da própria consciência e seus mecanismos, já no que tange à condição do homem singular, já no que toca à vida civil. A falsidade de uma ideia não obsta a produção de efeitos práticos a partir dela, não apenas nas mentes que não a distinguem corretamente, mas ainda naquelas que, conhecendo seu caráter inadequado, não podem porém deixar de ter em consideração uma ideia falsa quando uma afecção a faz presente. E, assim como é impossível, dada a natureza dos homens, excluir dela a imaginação, ainda que se trate de São Tomás, é também impossível constituir uma sociedade sem ideologia, ainda que se trate de uma sociedade comunista, como diz Althusser (2, p. 205). Por isso, uma revolução não transforma a ordem social sem combater a ideologia desta com outra ideologia, que possa limitar e contrapor-se aos efeitos da primeira na consciência social, tal como um modo de pensar limita outro modo de pensar na mente dos homens. 


\section{REFERÊNCIAS BIBLIOGRÁFICAS}

1. ALTHUSSER, L. Sobre a reprodução. Editora Vozes: Petrópolis, 1999. Análise crítica da teoria marxista (Pour Marx). Rio de Janeiro: Zahar Editores, 1967

3 Éléments d'autocritique. Paris: Hachette, 1974.

4.DELEUZE, G. Spinoza. Paris : P.U.F, 1970. Spinoza et le problème de l'expression. Paris: Les Editions de Minuit, 1968

6.SPINOZA, B. Ética. Trad. Thomaz Tadeu. Belo Horizonte: Autêntica, 2007.

7.SPINOZA, B. Tratado da reforma da inteligência. São Paulo: Martins Fontes, 2004.

8.SPINOZA, B. Tratado político. Lisboa: Editorial Estampa, 1977.

9.SPINOZA, B. Tratado teológico-político. São Paulo: Martins Fontes, 2003.

10.MARX, K. O capital, I. Rio de Janeiro: Civilização Brasileira, 2003.

11. Para a crítica da economia política. São Paulo: Nova Cultural, 1999.

12.MATHERON, A. Individu et communauté chez Spinoza. Paris : Les Editions de Minuit, 1988.

13.PIRES AURÉLIO, D. Introdução. In: ESPINOSA, B. Tratado Teológico-politico. São Paulo: Martins Fontes, 2003.

\section{THE CONSTITUTION OF THE SUBJECTIVITY AND THE FINALISM'S ILLUSION: ELEMENTS OF A THEORY OF IDEOLOGY}

Abstract: This text proposes to establish a correlation between Spinoza's conception of imagination and Althusserian ideology theory. Understood in its mode of functioning and in its effects over men's perception about their body, their ideas and the things that affect it, imagination would constitute, to Spinoza, the characteristic form of subjective conscience by operating in political world. Marked by the regularity and predictability of causal processes and by the reproduction of relations, political order would be present to imagination as a theological order, whose repetition would represent as universal truths the ideas of images of things in the form under which they would be present more recurrently to men perception. The stability of relations and images under which they represent it would correspond to stability of modes of thinking under which men represent themselves in political order. The contents of conscience - of politically structured imagination - would always be, from this point of view, ideological contents.

Keywords: Spinoza, imagination, Althusser, ideology.

\section{NOTAS}

1. As referências às obras de Spinoza designam-nas por abreviações - E, para a Ética; TP, para o Tratado político; TTP, para o Tratado teológico-político; TRI, para o Tratado da reforma do intelecto - e indicam o lugar de onde foram extraídas segundo a divisão original de partes e proposições (no caso da Ética) e de capítulos e parágrafos (no caso dos Tratados) que caracteriza suas respectivas estruturas. 